\title{
EDITORIAL
}

\section{Revista Sinapse: Onde Estamos e Para Onde Pretendemos Ir?}

\section{Sinapse Journal: Where Are We and Where do We Intend to Go?}

Delena Donato ${ }^{1}$, (D) Filipe Palavra ${ }^{2, *}$, (D) Catarina Resende de Oliveira ${ }^{3}$

1-Serviço de Documentação e Informação Científica / Centro Hospitalar e Universitário de Coimbra

2-Centro de Desenvolvimento da Criança - Neuropediatria, Hospital Pediátrico, Centro Hospitalar e Universitário de Coimbra; Instituto de Investigação Clínica e Biomédica de Coimbra (iCBR), Faculdade de Medicina, Universidade de Coimbra

3-Center for Innovative Biomedicine and Biotechnology and Center for Neurosciences (CIBB-CNC) / Universidade de Coimbra, Faculdade de Medicina

DOI: https://doi.org/10.46531/sinapse/ED/210003

\section{Onde estamos}

O ano de 2020 chegou ao fim. Foram muitos os desafios que, a todos os níveis, tivemos que enfrentar e procurar ultrapassar - uma doença infecciosa de expressão mundial abalou os fundamentos da nossa organização social e todos tivemos que, de alguma forma, aprender a conviver com uma nova realidade e a valorizar todo o investimento clínico e científico que nos permite, no advento de 2021 , ter esperança num programa de vacinação massiva que nos devolva o que considerávamos solidamente adquirido.

Também na Revista Sinapse o ano de 2020 teve impacto. Coincidindo com o primeiro ano do mandato de uma nova Direcção para a Sociedade Portuguesa de Neurologia (SPN), a Revista de todos nós, prestes a cumprir 20 anos de idade, foi desde logo assumida como uma prioridade absoluta e como um instrumento de divulgação científica ímpar, com muito potencial para crescer e fazer crescer a própria SPN. Ao longo deste ano, conseguiram-se publicar, no tempo adequado, os 4 números que fazem da Sinapse uma revista de cadência regular e tiragem trimestral. Conseguiu-se aumentar de forma significativa a submissão de trabalhos, sem os quais, diga-se, o primeiro objectivo não teria sido conseguido. Conseguiu-se consolidar o processo de modernização técnica e editorial, que permite à Sinapse ombrear com as melhores práticas a este nível - estando agora inscrita na CrossRef, os artigos são identificados com um DOI (digital object identifier), o que agiliza a sua inequívoca circulação pela web e encontra-se já disponível a publicação em "ahead of print" no site da Revista, acelerando a divulgação dos trabalhos aceites para publicação. Outra prática editorial que começou a ser seguida foi o uso do Open Researcher and Contributor ID (ORCID) para identificação de autores. $O$ seu uso evita qualquer ambiguidade resultante de semelhança entre nomes de autores, uma vez que substitui o respectivo nome por uma combinação numérica única.

Mas, apesar de todas estas conquistas, existem ainda algumas necessidades prementes, para que se alarguem os horizontes de influência da Revista. Estando indexada à SCOPUS, à EMBASE e ao ÍndexRMP, é objectivo de toda a estrutura editorial da Sinapse fazê-la crescer ainda mais, consolidando o seu relevante papel como instrumento de divulgação científica. Sabemos bem para onde pretendemos ir, mas a trajectória de crescimento far-se-á cumprindo determinados requisitos, para os quais é imprescindível a ajuda de todos os colaboradores da Revista.

\section{Para onde pretendemos ir?}

Para conseguir a desejada indexação em outras bases de dados bibliográficas internacionais, como a PubMed/Medline, a Web of Science da Clarivate Analytics e obter um factor de impacto atribuído pelo Journal Citation Reports (JCR), a Sinapse tem de manter a estratégia de melhoria da qualidade dos artigos que publica, expandindo a diversidade internacional e aumentando a acessibilidade a esses mesmos artigos. ' Conseguir estas indexações é uma missão de todos, exigindo
Informações/Informations: Editorial, publicado em Sinapse, Volume 20, Número

4, outubro-dezembro 2020.

Versão eletrónica em www. sinapse.pt

Editorial, published in Sinapse, Volume 20, Number 4, octoberdecember 2020.. Electronic version in www.sinapse.pt (C) Autor (es) (ou seu (s) empregador (es)) e Sinapse 2020. Reutilização permitida de acordo com CC BY-

NC. Nenhuma reutilização comercial.

(C) Author(s) (or their employer(s)) and Sinapse 2020. Re-use permitted under CC BYNC. No commercial re-use.

*Autor Correspondente / Corresponding Author: Filipe Palavra Centro de Desenvolvimento da Criança - Neuropediatria Hospital Pediátrico Centro Hospitalar e

Universitário de Coimbra Avenida Afonso Romão 3000-602 Coimbra, Portugal fpalavra@fmed.uc.pt

Recebido / Received: 2021-01-13 Aceite / Accepted: 2021-01-13 Publicado / Published: 2021-01-18 
esforço, tenacidade e capacidade de crítica. Mais importante que publicar um bom número é manter constante a qualidade científica, editorial e a produção (gráfica e informativa), pois são a constância e pontualidade que garantem a credibilidade e respeito da Revista a nível internacional.

A Sinapse cumpre as mesmas regras editoriais das revistas internacionais de prestígio, pois as suas instruções aos autores e políticas editoriais seguem Orientações Internacionais: International Committee of Medical Journal Editors (ICJME), Committee on Publication Ethics (COPE), EQUATOR Network, Council of Science Editors (CSE), Editorial Policy Statements; Declaration of Helsinki; descrição do processo de arbitragem científica (peer review + fast track); Declaração da Autoria e promoção da autoria responsável; evidência da declaração de Conflitos de Interesse; Formulários de consentimento informado; Permissões de republicação de imagens; Correcções e Retratações.

A Sinapse tem qualidade editorial, isto é, títulos que reflectem o conteúdo dos artigos; usa MeSH keywords; as referências bibliográficas dos artigos que publica são actuais; publica a história do artigo (datas de submissão/ aceitação/publicação); os artigos são publicados com as respectivas declarações de responsabilidade ética e de conflitos de interesse. Todavia, é necessário investir na promoção da Sinapse ${ }^{2}$ :

I. aumentando a sua visibilidade;

2. consciencializando os autores, líderes de opinião e grupos de trabalho para a qualidade da revista;

3. aumentando o número de submissões nacionais e internacionais;

4. melhorando a qualidade dos artigos publicados e permitindo que estes sejam citados por revistas internacionais de impacto;

5. publicando mais em língua inglesa, o que possibilitará alargar o leque de revisores, assim como aumentar a citação da Sinapse por autores internacionais;
6. convidando autores com trabalhos citados a publicar na revista;

7. identificando "hot topics" e convidando autores relevantes a publicar sobre esses temas;

8. aumentando a rapidez na publicação;

9. potenciando o papel dos revisores (peças-chave da qualidade dos trabalhos publicados), criando "normas para revisores";

10. promovendo a revista na web: nas redes socais genéricas (Facebook; Twitter; LinkedIN) e nas redes sociais académicas (Research Gate; Academia; Mendeley...).

Como conclusão, é possível afirmar que o que realmente promove a qualidade de uma revista é, primeiro e acima de tudo, a competência e dedicação dos seus editores e revisores, bem como a excelência do seu processo editorial. $O$ trabalho de conjunto entre a equipa editorial e um corpo de revisores altamente dedicados e motivados atrairá mais autores e melhores trabalhos, que permitirão atingir o nível de excelência que levará à indexação nas bases de dados que definimos como alvo. Depende de todos, editores, revisores e autores alcançar este tão almejado objectivo.

\section{Responsabilidades Éticas}

Conflitos de Interesse: Os autores declaram não possuir conflitos de interesse.

Suporte Financeiro: $O$ presente trabalho não foi suportado por nenhum subsídio ou bolsa.

Proveniência e Revisão por Pares: Comissionado; sem revisão externa por pares.

\section{Ethical Disclosures}

Conflicts of interest: The authors have no conflicts of interest to declare.

Financial Support: This work has not received any contribution grant or scholarship.

Provenance and Peer Review: Commissioned; Not externally peer reviewed.

\section{References / Referências}

1. Larivière $\mathrm{V}$, Haustein $\mathrm{S}$, Börner $\mathrm{K}$. Long-distance interdisciplinarity leads to higher scientific impact. PLoS One. 2015;10:e0122565. doi: 10.1371/journal.pone.0122565.

2. Donato $\mathrm{H}$. Understanding Journal Evaluation and Strategies to Increase Impact. Rev Port Pneumol. 2016;22:67-9. 